\title{
SOCIOCRÍTICA Y FENÓMENOS DE TRANSTEXTUALIDAD
}

\author{
Monique Carcaud-Macaire \\ Institut International de Sociocritique, \\ Montpellier, Francia
}

Las reflexiones que hoy propongo abordan un caso de variación transtextual, pues se trata de fenómenos de traspaso y de adaptación inevitable de un texto literario a un film o, a la inversa, de un film a otro filme ${ }^{1}$. Para formular en términos teóricos este asunto de los desplazamientos de una obra a otra, las distancias, las inscripciones de contenidos similares en apariencia, pero nítidamente diferenciados desde el punto de vista semiótico, me gustaría plantear aquí la noción de tercer interpretante. Ejemplos tomados del estudio de la adaptación del texto Der Tod in Venedig al filme Muerte en Venecia, entre otras, me servirán para explicitarlo².

La verdadera dificultad de argumentar la hipótesis propuesta nace del hecho de que primero habría que hacer una lectura sociocrítica completa del texto soporte, y una del nuevo texto producido, aún antes de plantear la cuestión de las razones y de las modalidades de la

1. Mi terminología no sigue la canónica de "géneros" y podría reprochárseme; sin embargo, voluntariamente no discrimino entre "adaptación" y "remake" en particular, ni entre "novelización" y "adaptación" tampoco. En efecto, mi exposición busca mostrar que una vez que estos fenómenos textuales pasan por la maquinaria sociocrítica, pierden toda la pertinencia que podrían tener en otros campos teóricos.

2. La aplicación de la metodología sociocrítica que sirve de base a esta reflexión teórica consiste en determinar, a partir de dif erentes incursiones críticas, la reemergencia de formas, la eventual convergencia de estructuraciones conceptuales en las estructuras textuales. 
transferencia operada de uno a otro. Sin embargo, los diferentes análisis efectuados sobre un cierto número de ejemplos han permitido verificarlo y destacarlo ampliamente: en el caso de una adaptación, existen circulaciones de tex to a tex to que no tienen que verúnicamente con lo anecdótico o con lo acontecido.

Desde el comienzo, una cuestión se impone: cómo explicar un elemento mórfico (v. infra), por ejemplo, en Muerte en Venecia, la oposición vida/muerte o la cuestión de lo bello, ¿cómo explicar entonces que una reestructuración reaparezca en contextos sociohistóricos y culturales distintos, a veces muy alejados unos de otros y en los cuales las mediaciones operatorias son diferentes? ¿Se podría pensar que se trata de un elemento residual en la cultura? ¿O bien resurge este elemento por circunstancias sociohistóricas y culturas particulares, que serían de alguna manera "portadoras" de lo que se podría llamar, por metáfora explicativa, "genes discursivos"? ¿Sería lo propio de estos "genes" convocar automáticamente (lo que podría formularse en términos del no consciente de formas textualizables) "gérmenes morfogenéticos", para retomar la expresión de Edmond Cros, que implican la morfogénesis específica del texto considerado? Para no citar más que este ejemplo, en los estudios de los filmes mencionados anteriormente hemos visto emerger de manera recurrente, pero según una textualización específica, la figura de la víctima emisaria que viene a subtender y sobrecodificar las representaciones textuales, ya se trate de Elizabeth D'Alnières, figura central de la novela Kamouraska, o de un escuadrón, en Les Croix de bois adaptación de Dorgelès por Raymond Bernard, la cual asigna la función expiatoria a una colectividad, a la que el filme de Howard Hawks sustituye por una figura individual, la del oficial.

Louis Quéré propone, en apoyo de su teoría, la noción de "tercer simbolizante", para designar la instancia que, en el marco de una comunicación orientada (un filme lo es también), organiza las operaciones necesarias a esta ${ }^{3}$. Esta noción operatoria intenta dar cuenta de

3. Louis Quéré, Dans miroirs équivoques. Aux origines de la communication moderne (Paris: Aubier, 1982). 
un funcionamiento. Poco ale jada parece esta noción de la del interpretante de Peirce, a la cual agrega implícitamente la teoría de los afectos; esta noción se interesa más por la comunicación intersubjetiva que por los actores de la comunicación. El funcionamiento descrito es el que determina lo que pasa entre el "espacio de realización" y el "espacio de recepción", es decir, todo lo que se recodifica y se transforma en operación de sentido en el momento del establecimiento del mensaje, y todo lo que ahí ocurre: recodificación, decriptaje, operaciones de afectos en el momento de su recepción. Toda producción textual ("espacio de realización") genera tiempo, significaciones y convoca afectos; la comunicación se logra, si la puesta en fase se opera con "el espacio de recepción", el cual genera, de la misma manera, tiempo, significaciones y convoca afectos.

Si se desplaza esta problemática del lugar de la comunicación hacia el campo de la creación cultural, se puede decir que el arreglo o la organización así operada es el de una puesta en fase entre la discursividad y las representaciones elaboradas por el acto de producción, y aquellas percibidas/producidas/construidas en el momento de la recepción por parte del destinatario/consumidor del objeto cultural. Llegados a este estadio de la reflexión, tenemos que postular que el tercer simbolizante, noción derivada de una teoría de la comunicación (o sea, comunicación vectorizada, elaboración y recepción de sentido a la vez), es historizado y puede no funcionar, por lo tanto, con la misma eficacia de una época a otra, ni de una sociedad a otra.

Se podría postular que, de la misma manera, en las prácticas culturales, cuando se confrontan con las prácticas discursivas (la escritura/transescritura), interviene una especie de dispositivo, de mecanismo de ordenamiento, de ajuste de sentido se podría decir, con el impulso sobredeterminante de las cincunstancias propias de los contextos de producción y de recepción de la obra cultural y que yo propongo llamar "tercer interpretante", por analogía con la fórmula de Louis Quéré, y para mantener de esta última toda su fecunda especificidad y extrapolándola, con un enfoque materialista, a partir de la teoría del signo de Charles S. Peirce. 
Acudir a la noción globalizante del tercero permite integrar la dimensión colectiva (que se afirma por medio de la mediación del artista) de la creación cultural y la doble incidencia, sobre esta última, de su contexto genético, por una parte, y la correspondiente modelización, por otra. Esto permite, igualmente, subrayar la ef icacia constitutiva de todo lo que compone el "no consciente sociocultural" dentro de la producción de las formas y las significaciones.

La noción de tercer interpretante designará, entonces, un espacio de mediación dinámica que dirige la operación de lectura del textosoporte, antes de la adaptación, y la misma operación de escritura, lo que explica que las actualizaciones características de la obra adaptada se atenúen, y aún más, se ignoren y lo que figuraba tan sólo potencialmente toma otra dimensión, incluso una forma concreta (realizaciones fenotextuales "agregadas", características de las adaptaciones). El mecanismo organizativo que constituye el tercer interpretante desconstruye el texto primero y lo redistribuye en material constitutivo de un nuevo tex to y de nuevas formas (de sentido); esta reestructuración es todavía más fuerte si hay transferencia de relaciones semióticas hacia otro sistema modelizante (y por este hecho, este es "responsable" por sí mismo de un cierto númerode reactivaciones o desplazamientos de significaciones).

Se trata, entonces, de un espacio de mediación (es decir, generador de alteridad esencial, para retomar una expresión mencionada al principio de esta exposición), de mediación dinámica, ya que los datos formales, las representaciones y los discursos allí se estructuran y se reestructuran (semióticamente, estos disfrutaban anteriormente de un estatus semiótico, a saber, de una realidad y de una autonomía en su contexto intratextual de origen). El funcionamiento del tercer interpretante "pone frente a frente" los elementos mórficos provenientes de contextos heterogéneos, creando el advenimiento del sentido, es decir, según los postulados teóricos de la sociocrítica, la morfogénesis.

En la terminología sociocrítica, la morfogénesis presupone una perspectiva materialista de la producción de sentido y de las 
significaciones: la textualización y no la intención de un autor genera, con el impulso de lo social materializado en discurso y representaciones, sus propias estructuraciones, en otras palabras, sus formas, frente a las cuales la operación de lectura organiza tensiones monosémicas provisionales.

Así se explica el hecho de que ciertos planos del filme Muerte en Venecia, por ejemplo el que muestra las cúpulas, invitan más a una lectura simbólica que a una mera identificación referencial. En ese sentido se puede decir que la imagen viscontina modeliza la Venecia manniana. Lo perceptivo/cognoscitivo activa y solicita al mismo tiempo, la memorización, la imaginación simbólica activa. El filme "construye" la imagen inicial propuesta por el texto literario, por intermedio de referencias y según modalidades consciente o no conscientemente producidas, pero identificables (también consciente o no conscientemente, por el sujeto cultural al que está destinada esta imagen) ${ }^{4}$.

Así, la Venecia del filme de Visconti difiere de la figurada dentro del texto de Mann o por este. Las descripciones propuestas, en efecto, la muestran como una ciudad cambiante. En la imagen, Venecia está asociada a lo lúgubre, a lo grisáceo, los planos relacionados, pero sin embargo indistintos por el hecho de la utilización de la contraluz o de los cuadros truncados, subrayan su aspecto mortuorio, alejándola de la imagen de Mann. "El notable silencio de la ciudad de las aguas que parecen recibir las voces con dulzura...", está totalmente ausente del filme, en el cual, por el contrario, se sustituye una caracterización legendaria de la ciudad por sonidos agresivos que vienen a perturbar con violencia la armonía generada por la música del filme, música tomada de Gustav Mahler. Aquí no hay nada de "magia", ni de "voces

4. Esto puede relacionarse con cierto número de nociones que se preguntan por la especificidad de la práctica de la creación cultural como semiotopo (Milagros Esquerro), "campos morfogenéticos" (Edmond Cros), en la medida en que la noción de tercer interpretante aspira a juntarlas y a verlas funcionar conjuntamente; igualmente puede relacionarse con las nociones de universales, doxa o la de "saberes comunes" (Charles Grivel). 
misteriosas", ni de interpelación que corresponda a esa imagen de Venecia vehiculizada por la cultura y que subyace en el texto de Mann. Del libro al filme, saber perceptivo y saber cognoscitivo son retrabajados por lo discursivo: la enunciación fílmica modeliza el contenido del texto inicial por intermedio de características que le son propias, e influencia la percepción/recepción de su destinatario: programación de la mirada, programación de la escucha que vienen a "condicionar", en el espectador, el doble proceso de identificación (de los datos de contenido), y de intelección en la base de la lectura y de las representaciones producidas, proceso que también está en la base de la comprensión del discurso sostenido por el filme Muerte en Venecia. Discurso autónomo y específico, pero que vehiculiza un discurso indiciado, marcado por su pertenencia a un contexto sociohistórico particular, sobre el libro de Thomas Mann, y por eso mismo mediatizado por la adaptación que opera como una deconstrucción "interpretante" de los interpretantes "dinámicos", según la expresión de Peirce, los cuales actúan sobre las actualizaciones/potencializaciones específicas del texto soporte.

Desde su comienzo, las dos $\mathrm{M}$ en $\mathrm{V}$ dejan percibir los índices de su significancia particular, las marcas de su naturaleza profunda, y las distancias que se observan en el análisis manifiestan la especificidad fundamental propia a cada uno de los textos: instauración de reglas narrativas, puesta en escena de una temática global, escritura particular que manipula materiales textuales diferenciados. La modelización de lo visual por lo sonoro en Visconti, la función narrativa del espacio claramente marcada en Mann, con esa doble imagen antagónica y culturalmente codificada de Venecia, constituyen representaciones específicas que señalan la complejidad de las reestructuraciones operadas en el momento del paso a la adaptación. A pesar de lo que a primera vista parece ser una identidad de contextos realistas, se nota que el sentido se instaura y funciona de manera diferente de un texto a otro. Hay que cuestionar esta diferencia, y sólo puede ser un cuestionamiento de las formas, es decir, de las estructuraciones 
propias de cada uno de los textos, con el fin de ver cómo ellas remiten a un pretextual diferente, y también con el propósito de poner en evidencia lo que la adaptación —en tantocreación cultural—significa comooperación de sentido en cada texto, primero, y de un texto al otro, después. Cada diferencia de forma es, entonces, una diferencia significante en la que se reproducen los elementos mórficos del genotexto ${ }^{5}$.

Así, los datos de focalización narrativa en el filme de Visconti remiten a problematizaciones (y por tanto, al trabajo de elementos mórficos particulares) con la acción de mediaciones (factores dinámicos de redistribución) que vienen a estructurarlas: problematización del tiempo, al igual que del estatuto de lo Real y de lo Representado. El nivel narratológico inscribe, pues, muy precisamente, los elementos conceptuales, transcodificados según esquemas que son propios de este nivel y que el análisis hace aparecer en otros niveles del filme, como en el de los contenidos temáticos, entre otros (/presencia/ $<\longrightarrow$ /ausencia/, /vida/ $\longrightarrow$ /muerte/, /presente/ $\longrightarrow$ /pasado/).

El estudio del montaje del sonido concluye con observaciones que van en el mismo sentido. Sin pretender una presentación exhaustiva, señalemos algunos aspectos. Más allá de su plasticidad y su poder emocional, la música, en lo que a ella concierne, funciona de manera relativamente compleja en el filme de Visconti. Primeramente es de notar la cualidad "osmótica" del montaje sonido-imagen. Por lo demás, la utilización de las sinfonías de G. Mahler transforma la serie musical en material composicional, narratológico e ideal a la vez, jugando con los leit-motivs; $y$, por la orquestación y el montaje, se asigna a dicha frase musical la función de embrague simbólico o de conector discursivo. La producción musical, el montaje osmótico sonido-imagen, contribuyen a tematizar y conceptualizar lo que la imagen y el espacio narrativo dan a leer. El tratamiento del sonido, además, corresponde a una verdadera puesta en escena.

5. $\quad$ Ver Edmond Cros, Théorie et practique sociocritiques (Montpellier: Editions du C.E.R.S., 1983). 
Por una parte, el sonido, al igual que el mismo montaje sonido/ imagen, hacen concretas las percepciones: el texto "construye" al espectador, facilitándole la experiencia de una materia artística visual y sonora. Por este hecho, el espectador se halla implicado en la estructura enunciativa del filme: este último hace de él un "sujeto perceptor". Por otro lado, en ciertos momentos, esta puesta en escena del filme nos informa más sobre la percepción "vivida" (la del personaje) que sobre la diégesis. Esto nos obliga, no tanto a construir un mensaje denotativo, situacional (Venecia, las góndolas, el chapoteo del agua), como a escuchar con el personaje principal Aschenbach, a experimentar sobre este modo subjetivo, el suyo, el chapoteo del agua sobre el casco de la embarcación, el continuo mascullar del gondolero. El filme nos invita entonces a identificar, si no a vivir, con el persona je la inquietud que — según nos dice la mímica señalada por un encuadre cerrado y un eje oblicuo inesperado_ está surgiendo. De esta forma, el espectador se encuentra ubicado en un lugar de escucha privilegiado: no es la acción lo que se sigue, sino la emoción interiorizada. En efecto, de repente, el chapoteo del agua, la voz del gondolero, pierden grados de realidad: el sonido se va disminuyendo al igual que el cuadro se angosta, selecciones contradictorias implican un ef ecto no-realista. Así, el lugar de escucha asignado es un punto en el que, por momentos, los sonidos concretos de lo real, como el ruido de los remos, ya no se escuchan más.

El grado de saber, al igual que las significaciones, se construyen en función de esas variaciones: cuando el filme produce el efecto de lectura inestabilidad/angustia/terror, se observa una amplificación del sonido sobre el que nuestra audición está colocada en toma directa; $\mathrm{y}$, al mismo tiempo, se construye un ef ecto de sentido Ineluctabilidad Tiempo/Muerte. Por el contrario, cuando se trata de temática y de conceptualización, el sonido se vuelve anecdótico y factual stricto sensu (por ejemplo, cuando se llega al Lido), y ya no se trata de la misma manera: se observa, en efecto, en ese momento, una ausencia de amplificación que se acompaña de una variabilidad del punto de escucha en función, notoriamente, de las distancias. 
Con estas pocas observaciones, se nota lo que la sociocrítica propone en relación con la narratología clásica, y lo que ella puede aportar en la comprensión y explicación de los fenómenos de transferencia propios de la adaptación. Las conclusiones de tipo semántico extraídas del estudio narratológico se tratan en tanto material conceptual - lo cual se aleja de la práctica narratológica que intenta la descripción profunda y detallada del funcionamiento narrativo o enunciativo, según los preestablecidos teóricos observados.

En relación con la perspectiva sociocrítica, la cuestión que debe plantearse es la del sustrato histórico que motiva las matrices discursivas, la del origen sociocultural de esta necesidad, perceptible en el filme de Visconti, que llega tal vez a cuestionar la realidad de los sentimientos, del ser, de la vida.

Plantear estas cuestiones sería mostrar cómo, definitivamente, la situación de enunciación propia del contexto genético del filme introduce sus modificaciones, en relación con esta perspectiva ya presente, pero con formas diferentes en Mann, modificaciones que se evidencian, por ejemplo, en el desquiciamiento que los "flashbacks" producen en la cronología. Estas alteraciones narrativas son el medio y la marca, en el filme de Visconti, de una "expansión" de ciertos términos portadores de la novela, bajo el efecto de mediaciones discursivas que las modelizan ${ }^{6}$.

En lo concerniente al advenimiento del sentido, todo gira alrededor de la perturbación de la cronología y de la progresión hacia la abstracción, que se efectúa por la instauración progresiva de una mostración poética, nuevas estructuras textuales propuestas en el filme de

6. Numerosos índices permiten evidenciar la superación de la estructuración diferencial de elementos mórficos; así, la Muerte, simple elemento temático, más bien declinado bajo el modo de la ilustración en el texto de Mann, es lo que en el filme de Visconti estructura desde el interior las representaciones, las realizaciones fenotextuales, diegéticas, temáticas o extrasemánticas - por ejemplo, la puesta en imagen de las aguas muertas de la laguna, el efecto de surgimiento fuera de la nada que imponen los primeros planos. El primer "flashback", elemento "extrasemántico", que introduce explícitamente la muerte como tema discursivo, lo demuestra en su tratamiento técnico: no "motivado", no "gramaticalizado". 
Visconti. Al mismo tiempo que reemiten a la construcción de un ambiente perceptivo, los "flashbacks" introducen el debate conceptual que toma por tema, por sede y punto de partida, el discurso letrado de Mann, que él desplaza hacia la abstracción: el filme problematiza, es decir, cuestiona y prácticamente argumenta a través de sus formas lo que en el texto literario se presenta como referencias (ver las citas, las transposiciones, las aserciones que componen las digresiones narrativas, cuya motivación reside en su valor explicativo en relación con el personaje dual, bifacial, dividido entre la ebriedad y el sueño, entre lo apolíneo y lo dionisíaco).

Este conjunto de significaciones constituye, al lado de los contextos realistas, otra identidad aparente entre los dos textos, a saber, el discurso del letrado: una parte importante de las referencias son las mismas (Nietzsche, Fausto) pero, y allí reside la huella del funcionamiento semiótico, no son los mismos fragmentos de tal o cual referencia los que se explotan; lo que es más, no se utilizan de la misma manera, su distribución no es la misma. Trátese ya de la cuestión de lo Bello, ya de la figura de la Decadencia, ya del concepto de Tiempo o del de la Muerte, elementos mórficos de estructuración que hemos aislado, las actualizaciones no son idénticas, no acarrean, en consecuencia, los mismos discursos. En efecto, desplazan, al descontextualizarlas y estructurarlas de nuevo, las configuraciones discursivas que dan al texto de Mann su especificidad y del que señalan su pertenencia a una formación sociodiscursiva precisa.

Si se sigue la propuesta crítica de Cros, enunciada en su teorización de la producción cultural y la producción del sentido por las formas artísticas, se admitirá que si hay elementos mórficos prestos a ser movilizados por la creación cultural, es porque el contexto de esta motiva esta atracción, entraña una re-actualización de estos elementos confrontados a problematizaciones nuevas en el discurso social. En el caso preciso que estudiamos, la mediación de la filosofía nietzschiana existe en los dos casos, y la escritura teje las equivalencias; lo que parrece ser la fuerza de atracción es la coincidencia que uno puede 
observar entre la toma de conciencia, que se enuncia en cada uno de los textos, por los intelectuales, de lo que parece ser el final de un mundo, y hasta el fin del mundo. Frente a esta constatación que se transparenta en las representaciones propias de cada texto (por ejemplo en la pintura social que se observa, las modalidades de la puesta en escena, o incluso en las selecciones formales), se inscribe, en cada una, una posición por adoptar: la espera pasiva (Der Tod in Venedig), o el repliegue del hombre-que-se-opone Muerte en Venecia). En este sentido, la textualidad en Mann reproduce una práctica discursiva (la exaltación del alma alemana y el ascenso de una Gran Alemania), y una práctica social (la aceptación pasiva); mientras que en Visconti la textualidad parece subvertir una práctica discursiva (respuesta individualista a la ideología de mayo de 1968).

En varias ocasiones, con el fin de calificar la empresa de transescritura, he evocado la idea de la desestabilización de lo que podría llamarse "morfogenes", características del preconstruido textual anterior y de su reajuste con la acción de elementos que acarrean las estructuraciones nuevas, a saber, los "elementos mórficos" surgidos de otros conjuntos de estructuración mórfica y pertenecientes a otros contextos discursivos.

Para perfeccionar esta teorización, por el momento se trata de cuestionar lo que ocurre exactamente en el nivel de los elementos mórficos, lo que ahí sucede en relación con las estructuras ideosémicas: en efecto, no se puede dejar de enfrentar la problemática de la organización eventual y de la incidencia concreta del elemento mórfico. Sólo el análisis sistemático de un corpus representativo de textos permitirá teorizar con el detalle y la certidumbre requeridos este aspecto de la cuestión teórica mencionada.

Así, curiosamente, un elemento mórfico particular, una figuración construida, reaparece en varios textos estudiados hasta el presente: la víctima emisaria. La noción sacrificial está presente explícitamente o en filigrana, en la trama de los textos en cuestión.

La constatación de esta re-emergencia puede constituir el punto de partida de la reflexión sobre los elementos mórficos: ¿de dónde 
proviene el que esta figura vuelva y sea objeto de una reinterpretación por sujetos culturales distintos, en épocas distintas?

La teoría de los campos morfogenéticos propuesta por Edmond Cros puede ofrecer los elementos necesarios para elaborar una respuesta satisfactoria a esta cuestión. El elemento mórfico de la cuestión sacrificial aparece en obras culturales que pertenecen a contextos culturales marcados por la inestabilidad, incluso, la desestructuración.

Partiendo de ahí, si uno reconsidera la teoría de las mediaciones de modo que se pueda cruzar con los procesos de adaptación, habría que postular que, en un primer momento, se trata de que el sentido se "ajuste", entre lo que llamaríamos por comodidad "gramática de producción" y "gramática de recepción", modelizadas por el estado de lengua, de sociedad y de discurso propio a la situación contextual que entrañan los almacenamientos y códigos de la comunicación orientada, al igual que la parte de lo emocional, de la intención y de lo no consciente. En un segundo momento, en cuanto a la empresa de adaptación, interviene el trabajo de estructuración ya explicitado: es en este nivel donde las constricciones particulares ligadas a la modelización específica (literatura, cine, arte plástica como el afiche o el cuadro, por ejemplo) pueden intervenir para desorganizar, reajustar formas y, por lo tanto, el sentido. El tercer interpretante dirige, entonces, la desestabilización provisional de los "genes" mórficos y luego su reajuste según una nueva (para seguir con la metáfora biológica) "programación" genética, así por ejemplo: a. la Muerte como elemento mórfico; y b. la función sacrificial. Ausente del libro, ella está presente en Muerte en Venecia: los signos destacados son signos "canónicos" de la estructuración cultural. La presencia de esta estructura en el discurso profundo del filme permite múltiples hipótesis en cuanto al filme de Visconti; por una parte, la identificación de una cierta visión existencialista: ser es ser víctima; $y$, por otra parte, de un discurso sobre el arte y el mediador cultural donde se encuentra redistribuida la figura del poeta maldito.

La presencia estructural, en fin, de la función sacrificial como respuesta del sujeto colectivo preso o amenazado por la dislocación 
(cf. el decadentismo que el análisis hace aparecer como estructura discursiva mediadora, lo mismo que el barroco, otro elemento mórfico). Esta figura de la víctima emisaria, para que se comprenda bien, debe ponerse entonces en relación con otras estructuraciones del texto fílmico, en particular con las oposiciones textuales que ahí se observan: libertad/determinismo, ser/apariencia, individuo/grupo, inocencia/culpabilidad.

Toda nueva escritura, para retomar la sugerencia fecunda de la obra de Edmond Cros, corresponde a un engendramiento de formas, estrechamente ligadas a la especificidad del contexto de la creación artística. Todo texto se transtextualiza, entonces, convirtiéndose en material preconstruido, es decir, conjunto de realizaciones discursivas y de formas, pero también, si se quiere admitir la teoría aquí presente, conjunto de potencialidades formales y discursivas, desde el momento en que es objeto de una manipulación por otra práctica de escritura. La adaptación hace que se encuentren "conflictos discursivos" (por ejemplo, la filosofía de Nietzsche y los mitos escatológicos, el idealismo y el materialismo), "encuentro" que implica la valorización de una potencialidad discursiva o la selección de un elemento mórfico (de una estructuración), como la tensión Apolo/Dionisios, por ejemplo. Este juego de estructuraciones produce la transtextualización. Esta última, repitámoslo, se hace más compleja cuando se trata de pasar de una forma modelizante a otra. En el caso de Muerte en Venecia, más allá de la identidad de elementos fenotextuales, la alteridad se instala y las diferencias así instauradas son portadoras de valores simbólicos y sociales.

La adaptación, literalmente elaboración/transformación a partir de algo, plantea la problemática del modelo ("pattern") ${ }^{7}$ y de la reescritura, y hace intervenir la noción de sistema modelizante del que

7. Modelo cualquiera: ya sea formal, estético -incluso personaje o tema ya dotado por la cultura o la Historia de un simbolismo colectivo; citemos por ejemplo Carmen, Cosette, y en el caso preciso, Fausto. 
un texto porta siempre las huellas. La cuestión de la adaptación implica, entonces, la cuestión de la forma y así, la forma es el sentido.

En la medida en que ella interroga la producción de sentido a partir de las formas de un objeto cultural, la sociocrítica of rece las herramientas metodológicas que permiten dar cuenta, de una manera relativamente satisfactoria, de los fenómenos de transferencia que intervienen cuando un texto literario se convierte en material de un filme. Ella permite también proponer una teoría de la adaptación.

Osemos, al final de cuentas, dirigimos hacia lo que podría ser una definición de la adaptación (ver infra, la teorización del proceso del tercer interpretante), como la redistribución mediatizada (cf. la escritura y la contextualización) de una mediación predeterminada: la lectura; predeterminada, pues esta se encuentra también (precisémoslo, por la organización operada por el tercer interpretante) constituida por los datos extratextuales y paratextuales.

Como noción teórica que pretende precisar la naturaleza de un fenómeno, el tercer interpretante constituye, si se quiere aceptar la metáfora, un "generador de funcionamiento semiótico" en el proceso de transtextualización (es decir, por la práctica de transescritura, transferencia/redistribución de preconstruido, de interdiscurso y de elementos mórficos), haya o no pasaje de un sistema modelizante a otro. En esta perspectiva, lo que se ha convenido en llamar "remake" constituye solamente una modalidad específica de la adaptación como forma de creación cultural, siendo el punto común de ambas la operación compleja de lectura (construcción distributiva sobredeterminada) y de producción (redistribución estructurante mediatizada) que las caracteriza. 